\title{
POLÍtICA DE EDUCAÇÃo ESPECIAL NA PERSPECTIVA DA EDUCAÇÃO INCLUSIVA
}

ARAUJO, Marciano Vieira de ${ }^{1}$

ARAUJO, Marciano Vieira de. Política de Educação Especial na Perspectiva da Educação Inclusiva. Revista Científica Multidisciplinar Núcleo do Conhecimento. Ano 02, Ed. 01, Vol. 16. pp. 566-575, Março de 2017. ISSN:2448-0959

\section{RESUMO}

O artigo trata da política de educação especial na perspectiva da educação inclusiva, tem como objetivo mostrar o desenvolvimento da educação especial, quais os grupos que sofrem exclusão mesmo não sendo alunos especiais e a inclusão com as abordagens dos princípios da educação. Para fundamentar esse estudo buscou-se pautar-se em vários teóricos como: Gadotti, Documentos oficiais que trata da educação especial com perspectiva inclusiva como: CF, LDB, PNEE, MEC/SEESP UNESCO. A metodologia utilizada foi de revisão literária pautada nos documentos citados e outros artigos de defensores da inclusão dos alunos com necessidades educacionais especiais nos estabelecimentos de ensino. Podemos concluir que a luta por uma verdadeira inclusão é árdua e que vários movimentos para sucesso dessa estão sendo traçados havendo vitorias e derrotas, essas são validas, pois, levam sempre a uma reestruturação das políticas em prol da inclusão educacional e social do aluno com necessidades educacionais especiais.

Palavras-chave: Desenvolvimento, Abordagens, Exclusão, Alunos.

\footnotetext{
${ }^{1}$ Mestrando em Educação pela Universidade Anne Sullivan- Conclusão de Defesa de Tese; Especializado em Ensino de História e Geografia pela Faculdade Stella Maris; Especializado em Psicopedagogia Clinica Institucional pela Universidade Vale do Acaraú; Graduado- Licenciatura em Pedagogia pela Universidade Vale do Acaraú.
} 


\section{INTRODUÇÃO}

A inclusão dos alunos com necessidades educacionais especiais, nas escolas, publica e privadas, apresenta uma trajetória de desafios, principalmente por ser uma alternativa para minimizar o problema da exclusão educacional e social.

Diante dos desafios percebemos uma crescente ideia por uma inclusão verdadeira, mas, está tão sonhada inclusão acontece de maneira diferenciada de acordo com o desenvolvimento econômico dos países.

Não podemos negar que a luta pela inclusão conta com reestruturação de políticas públicas para assegurar ao aluno com necessidade educacional especial uma educação de qualidade com respeito as suas limitações e potencialidades, e que educadores, principalmente das escolas públicas manifestam preocupação com a inclusão desses alunos, estes alegam não estarem preparados para ao receber, pois, não receberam formação na área e seu conhecimento sobre as necessidades desses alunos é muito pouca.

Sabemos que a exclusão de muitos grupos está presente na sociedade, uma das exclusões que podemos ressaltar é a das meninas que engravidam quando ainda estão nas escolas, quando isso acontece, ficam envergonhadas chegando até mesmo a abandoná-la.

Pautados nas abordagens dos princípios da educação que estão nos documentos oficiais como: CF, LDB, PNEE, MEC/SEESP, ECA e alguns defensores da inclusão, estes acreditaram, que, a inclusão seja possível, pois, como diz a Constituição Federal Brasileira: "Educação é um direito de todos, sem preconceito de origem, raça, sexo, cor, idade ou quaisquer outras formas de discriminação". Falar sobre inclusão, é importante lembrar, da primeira conferência, a de Salamanca, essa que foi uma estrutura de ação em Educação Especial adotada pela conferência mundial em Educação Especial organizada pelo governo da Espanha em cooperação com a UNESCO, realizada em Salamanca entre 7 e 10 de junho de 1994. Assim esse artigo 
tem como objetivo mostrar o desenvolvimento da educação especial, quais os grupos que sofrem exclusão e as abordagens dos princípios de educação.

\section{DESENVOLVIMENTO DA EDUCAÇÃO ESPECIAL}

Falando da inclusão entre países ricos e pobres, veremos maneiras diferenciadas como esta acontece, um deles é que, nos países pobres muitas crianças com necessidades educacionais especiais nunca entraram em uma instituição educacional e nos países considerados ricos estes alunos deixam as escolas sem qualificações que venham ajudar suas vidas, outros são colocados em regimes especiais sem experiências educacionais que os desenvolvam e por último, alguns abandonam as escolas por não verem atrativos nelas para sua vivencia como pessoas.

Nossas leituras sobre o tema inclusão nos levam a constatar que trata-se de uma temática desafiadora para nossa sociedade, no tocante ao desenvolvimento de lutas para que crianças especiais tenham seu espaço dentro das instituições educacionais vem crescendo e políticas públicas estão sendo colocadas em pratica, mas, infelizmente, profissionais da educação mostram uma resistência a consumação de uma inclusão plena desrespeitando os direitos adquiridos por esse grupo de alunos que dentro da escola sofrem com atitudes de preconceitos por parte dos alunos ditos normais, até mesmo dos educadores e gestores.

A política de educação inclusiva tem como objetivo a eliminação da exclusão social e educacional e que seja respeitada a diversidade de raça, classe social, etnia, religião, gênero e habilidades que os alunos trazem de suas vivencias e principalmente de que a educação é um direito de todos, sendo este princípio respeitado, fundamentalmente a sociedade se tornaria mais justa e solidaria. Respaldamos este pensamento no documento Plano de Desenvolvimento da Educação, neste, é reafirmado à visão de que a educação busca superar a oposição entre educação regular e educação especial, vejamos:

Contrariando a concepção sistêmica da transversalidade da educação especial nos diferentes níveis, etapas e modalidades de ensino, a educação não se estruturou na RC: 7453

Disponível em: https://www.nucleodoconhecimento.com.br/educacao/politica-de-educacaoespecial 
perspectiva da inclusão e do atendimento às necessidades educacionais especiais, limitando, o cumprimento, do princípio constitucional que prevê a igualdade de condições para o acesso e permanência na escola e a continuidade nos níveis mais elevados de ensino. (PDE, 2007, P. 09)

Devemos entender, portanto, que uma criança portadora de necessidades educacionais especiais tem o direito a uma escolarização.

Transportando o desenvolvimento da educação especial para o início dos movimentos em prol da inclusão do aluno especial, chegaremos a Conferencia Mundial de Salamanca ocorrida 22 anos atrás, esta endossou a ideia da educação inclusiva da UNESCO (1994) este documento que é internacionalmente é o mais significativo de todos os documentos que já apareceu da área de educação especial.

A Declaração de Salamanca defende que escolas regulares que tenha orientação para inclusão, estas constituem "o meio mais eficaz de combater atitudes discriminatórias, construindo uma sociedade inclusiva e atingindo educação para todos". No documento da UNESCO, este sugere que tais escolas com orientações inclusivas, podem "proporcionar educação eficaz para a maioria das crianças, melhorar a eficiência e, consequentemente, o custo-benefício de todo o sistema educacional". (UNESCO, 1994). O processo de mudanças com diretrizes nacionais para a educação especial na educação básica, traz uma resolução, onde seu artigo 20 determina que:

Os sistemas de ensino devem matricular todos os alunos, cabendo às escolas organizarem-se para o atendimento aos educandos com necessidades educacionais especiais, assegurando as condições necessárias para uma educação de qualidade para todos. (MEC/SEESP, 2001).

Da Declaração de Salamanca aos dias atuais, foram envolvidos vários estágios ao desenvolvimento da educação especial explorando diferentes formas de atender a criança com necessidades educacionais especiais e as que apresentam dificuldades 
de aprendizagem para que estas não sofram segregação dentro da instituição educacional.

A história da educação especial mostra que em uma das etapas na tentativa de buscar a integração do aluno especial, estes foram colocados em um sistema de educação separado dos demais, as chamadas escolas especiais, nos anos recentes, esse sistema foi questionado tanto do ponto de vista dos direitos humanos como da sua eficácia ao desenvolvimento desses alunos como pessoa, seria preciso naturalmente, a aplicação de práticas humanísticas dos envolvidos no contexto educacional dentro do processo de ensino aprendizagem para respeito às limitações e potencialidades que trazem de suas vivencias.

\section{INCLUSÃO AOS GRUPOS QUE SOFREM EXCLUSÃO}

Constatamos que os alunos com necessidades educacionais especiais sofrem discriminação, mas, que não são só eles, vemos a exclusão em outros grupos como: meninas que engravidam ou têm bebês enquanto estão na escola, gordos, negros, os que mostram atitudes homossexuais, entre outros. A exclusão educacional se referi as crianças que são excluídas das salas de aula por causa de seu comportamento diferenciado.

Nossa Constituição Federal de 1988 nos artigos 205 e 206 colocam como objetivos fundamentais: "promover o bem de todos, sem preconceitos de origem, raça, sexo, cor, idade e quaisquer outras formas de discriminação" (art. $3^{\circ}$ inciso IV). Vejamos os artigos 205 e 206:

Art. 205: a educação como um direito de todos, garantindo o pleno desenvolvimento da pessoa, o exercício da cidadania e a qualificação para o trabalho.

Art. 206, inciso I estabelece a: "igualdade de condições de acesso e permanência na escola", como um dos princípios para o ensino e, garante-o, como dever do Estado, a oferta do atendimento educacional especializado, preferencialmente na rede regular de ensino (art. 208). 
Ao lermos o Estatuto da Criança e do Adolescente (ECA) - Lei no. 8.069/90, artigo 55, um reforço aos dispositivos legais supracitados ao determinar que: "os pais ou responsáveis têm a obrigação de matricular seus filhos ou pupilos na rede regular de ensino" (ECA, 1990).

Ao ser publicada a Política Nacional de Educação Especial em 1994, este orienta o processo de "integração instrucional" que condiciona o acesso às classes comuns do ensino regular àqueles que "(...) possuem condições de acompanhar e desenvolver as atividades curriculares programadas do ensino comum, no mesmo ritmo que os alunos ditos normais". (PNEE, 1994, p.19).

As discussões sobre inclusão parecem indicar que pode haver alguns processos comuns que ligam as diferentes formas de exclusão de crianças com deficiências, que foram excluídas de suas escolas por razoes disciplinares e de pessoas que vivem em comunidades pobres este fato leva a exploração de processos de estruturas sociais e educacionais.

Procuramos informações sobre inclusão também no documento LDB - Lei de Diretrizes e Base da Educação Nacional Lei no. 9.394/96, artigo 59, este diz que:

Os sistemas de ensino devem assegurar aos alunos currículo, métodos, recursos e organização específicos para atender as necessidades; assegurar a terminalidade especifica aqueles que não atingiram o nível exigido para a conclusão do ensino fundamental, em virtude de suas deficiências e, a aceleração de estudos aos superdotados para a conclusão do programa escolar. Também define, dentre as normas para a organização da educação básica, a "possibilidade de avanço nos cursos e nas series mediante verificação do aprendizado" (art.24, inciso V) e "|...| oportunidades educacionais apropriadas, consideradas as características do alunado, seus interesses, condições de vida e de trabalho, mediante cursos e exames" (art. 37). (LDB, 9.394/96, art. 59)

Todos os movimentos pela inclusão de alunos com necessidades educacionais especiais ganham força pelo mundo, começa a crescer a procura de matriculas para

Disponível em: https://www.nucleodoconhecimento.com.br/educacao/politica-de-educacaoespecial 
crianças especiais nas escolas regulares pelos responsáveis, uma luta para que essas escolas recebam-nas e valorizem-nas respeitando suas diferenças e as tratem igualitariamente.

Defensores da inclusão seguem sua luta por uma educação de qualidade para todos e analisam mudanças na estrutura do MEC em relação à educação especial, pois, embora tenha havido aumento do número de alunos com necessidades educacionais especiais no sistema de ensino brasileiro, estes ainda enfrentam barreiras para sua aceitação nas comunidades escolares e terem oportunidades para aprender com conteúdos curriculares que os desenvolvam escolarmente e com relevância a sua formação humana.

Percebemos através dos estudos de abordagem do assunto inclusão que a luta é árdua, e que as escolas estão despreparadas ao atendimento de alunos com necessidades educacionais especiais, estes enfrentam barreiras até dos profissionais de educação que dizem não estarem preparados a recebê-los e atendê-los adequadamente.

$\mathrm{Na}$ Convenção sobre os direitos das pessoas com deficiência, aprovada pela ONU em 2006 estabelece que: "os estados devem assegurar um sistema de educação inclusiva em todos os níveis de ensino, em ambientes que maximizem o desenvolvimento acadêmico e social compatível com a meta de inclusão plena".

\section{INCLUSÃO COMO ABORDAGEM DE PRINCÍPIOS A EDUCAÇÃO}

Para pensar educação com essa abordagem, devemos ver cinco formas que indicam significativamente dados de inclusão para as pessoas com necessidades educacionais especiais, essas cinco formas colocadas no artigo descrito por Mel Ainscow que são:

1. Inclusão referente à deficiência e a necessidade de educação especial; 2. Inclusão como resposta a exclusões disciplinares;

3. Inclusão que diz respeito a todos os grupos vulneráveis a exclusão;

Disponível em: https://www.nucleodoconhecimento.com.br/educacao/politica-de-educacaoespecial 
4. Inclusão como forma de promover escola para todos;

5. Inclusão como educação para todos.

Essas formas defendidas pela pesquisadora, que segundo ela, queria identificar "como a inclusão tem significado para a cultura, políticas e práticas de uma escola", escola essa que desenvolve comprometidamente, a inclusão de alunos com necessidades educacionais especiais. Percebemos no pensamento descrito que a inclusão está envolvida com valores a serem implantados nas escolas que não aceitam descriminação aos portadores de deficiência em suas ações pedagógicas e interativas desses com os outros alunos que não portam deficiência.

Sabemos que a inclusão envolve todos que estão inseridos no processo de ensino aprendizagem, é preciso traçar caminho que leve a todos lutar por uma educação transformadora e significativa na vida dos que a procura com atitudes solidarias sendo os valores morais colocados em pratica. Para isso é preciso que:

- Os processos educacionais aumentem a participação dos estudantes;

- Haja redução de atitudes de exclusão por parte dos educandos e educadores;

- Implantação de currículo respeitando as potencialidades e habilidades limitadas dos alunos com necessidades educacionais especiais;

- Reestruturação de culturas, políticas e práticas das escolas de forma que essas aceitem a diversidade dos educandos com necessidades educacionais especiais.

Sabemos que a inclusão tem vantagens, mas, também desvantagens, embora não tenhamos encontrado nenhum pesquisador que tenha esta opinião, os aspectos da inclusão têm importância especial, principalmente para os alunos com necessidades educacionais especiais, pois, ela abrange todas as crianças e jovens, está vinculada a exclusão no sentido que envolve a inclusão envolve o combate ativo da exclusão.

Nas escolas onde o desenvolvimento do ser é trabalhado, entendemos que o educando deva praticar sua cidadania, solidariedade e interação social. Baseado nesse preceito, Gadotti diz que: "O homem, na sua essência, é um ser inacabado, 
num processo contínuo de vir a ser, mediado pelo acesso às interações sociais". (GADOTTI, 1999, p. 44).

Para falar de inclusão, devemos lembrar, da Conferencia Mundial de Salamanca ocorrida na Espanha, esta traçou normas para oportunizar as pessoas com deficiência a entrarem no sistema educacional de ensino, descreveremos, a seguir, os princípios básicos dessa Conferencia:

Reconvocando as várias declarações das Nações Unidas que culminaram no documento das Nações Unidas "Regras Padrões sobre Equalização de Oportunidades para Pessoas com Deficiências", o qual demanda que os Estados assegurem que a educação de pessoas com deficiências seja parte integrante do sistema educacional. Notando com satisfação um incremento no envolvimento de governos, grupos de advocacia, comunidades e pais, e em particular de organizações de pessoas com deficiências, na busca pela melhoria do acesso à educação para a maioria daqueles cujas necessidades especiais ainda se encontram desprovidas; e reconhecendo como evidência para tal envolvimento a participação ativa do alto nível de representantes e de vários governos, agências especializadas, e organizações intergovernamentais naquela Conferência Mundial. (SALAMANCA, 1994)

Portanto, objetivando mostrar caminhos que levem alunos com necessidades educacionais especiais a uma inclusão educacional e social, este estudo tentou pautar-se em artigos escritos anteriormente e nos documentos oficiais que norteiam as políticas de educação especial na perspectiva da educação inclusiva, detectamos também, que, as escolas não oferecem condições necessárias para o atendimento dessas crianças e que os professores consideram-se despreparados para recebê-los e inseri-los no contexto educacional com atividades que venham integrá-los na sala de aula com os colegas.

\section{CONSIDERAÇÕES FINAIS}

A inclusão escolar tem início na educação infantil, onde se desenvolvem as bases necessárias para a construção do conhecimento e seu desenvolvimento global. Mas,

RC: 7453

Disponível em: https://www.nucleodoconhecimento.com.br/educacao/politica-de-educacaoespecial 
para os alunos com necessidades educacionais especiais, essa é a fase mais difícil de uma inclusão educacional, este fato se dar, às vezes, até mesmo por conta da família temer ou ter vergonha de mostrar que tem filhos com algum tipo de deficiência.

Sabemos que o acesso às formas diferenciadas de comunicação, a riqueza de estímulos nos aspectos físicos, emocionais, cognitivos, psicomotores e sociais e a convivência com as diferenças favorecem as relações interpessoais, o respeito e a valorização da criança, mas, as barreiras enfrentadas pelos alunos com necessidades educacionais especiais são enormes em conseguir esta tão sonhada inclusão.

Pesquisadores mostram que é do nascimento aos três anos que as crianças precisam de atendimento educacional especializado, pois este, trabalha por meio de serviços de intervenção precoce que objetivando otimização do processo de desenvolvimento e aprendizagem em interface com os serviços de saúde e assistência social. Em todas as etapas e modalidades da educação básica, o atendimento educacional especializado é organizado para apoiar o desenvolvimento dos alunos, constituindo oferta obrigatória dos sistemas de ensino e deve ser realizado no turno inverso ao da classe comum, na própria escola ou centro especializado que realize esse serviço educacional, tão importante no auxílio a inclusão dos alunos com necessidades educacionais especiais.

Desse modo, entendemos que, com o desenvolvimento de políticas públicas em prol de ações da educação especial possibilitando e ampliando as oportunidades de escolarização, formação para a inserção no mundo do trabalho e efetiva participação social tem envolvido muitas classes de nossa sociedade refletindo nos avanços para a inclusão do aluno com necessidades educacionais especiais.

\section{REFERÊNCIAS}

BRASIL. Ministério da Educação. Lei de Diretrizes e Bases da Educação Nacional. LDB 4.024, de 20 de dezembro de 1961. 
BRASIL. Ministério da Educação. Lei de Diretrizes e Bases da Educação Nacional. LDB 5.692, de 11 de agosto de 1971.

BRASIL. Constituição da República Federativa do Brasil. Brasília: Imprensa Oficial, 1988.

BRASIL. Ministério da Educação. Secretaria de Educação Especial. Lei №. 7.853, de 24 de outubro de 1989.

BRASIL. Estatuto da Criança e do Adolescente no Brasil. Lei no 8.069, de 13 de julho de 1990.

BRASIL. Declaração Mundial sobre Educação para Todos: plano de ação para satisfazer as necessidades básicas de aprendizagem. UNESCO, Jomtiem/Tailândia, 1990.

BRASIL. Declaração de Salamanca e linha de ação sobre necessidades educativas especiais. Brasília: UNESCO, 1994.

BRASIL. Ministério da Educação. Secretaria de Educação Especial. Política Nacional de Educação Especial. Brasília: MEC/SEESP, 1994.

BRASIL. Ministério da Educação. Lei de Diretrizes e Bases da Educação Nacional. LDB 9.394, de 20 de dezembro de 1996.

BRASIL. Ministério da Educação. Secretaria de Educação Especial. Decreto no 3.298, de 20 de dezembro de 1999.

BRASIL. Ministério da Educação. Secretaria de Educação Especial. Diretrizes Nacionais para a Educação Especial na Educação Básica. Brasília: MEC/SEESP, 2001. 